The scale of the project and the number of routes being explored at once have led to comparisons with the Manhattan Project, the US rush to devise nuclear weapons at the end of the Second World War. On IAEA estimates, assuming the project started in the late $1970 \mathrm{~s}$, it could have cost $\$ 10,000-\$ 12,000$ million, even allowing for low oil and labour costs.

The Iraqis have denied that they were trying to connect all these routes together, for example using the enriched uranium from the centrifuges to feed the calutrons to increase their efficiency. It looks more, according to the IAEA, as if they were pursuing all routes until they found a winner.

On IAEA estimates, through either the centrifuges or the EMIS, they would have had enough enriched uranium to equip a nuclear weapon within two years.

It seems unlikely that import restrictions have proved a big constraint, either on materials or choice of programme. It certainly would have needed foreign technical expertise in the centrifuge design. In this area the IAEA believes it has identified several names. Further missions will be needed to establish the scale of the centrifuge project. The IAEA expects to have finished by the end of 1991. However, removal of the fuel rods from the Tuwaitha reactors, at a cost of perhaps $\$ 20$ million, will take longer.

The scale of the activity previously undetected raises questions both for the intelligence agencies and for the IAEA in its role as watchdog of the NPT. The US military appears to have been unaware during the Gulf War of several of the largest sites uncovered by the IAEA. It was only after a first bombing of AlTarmiya military complex that aerial photographs gave a clue to the EMIS activity inside. Ash Sharkat, Tarmiya's twin, was not designated a high priority target in the war and was bombed, according to Kay, only because a pilot returning from Baghdad had unused bombs. Al-Farat, the centrifuge production centre, escaped entirely unbombed.

It would also be astonishing if the discoveries did not raise questions for the IAEA governors' meeting on 11 September. The last IAEA inspection was in November 1990 . The IAEA, unsurprisingly, is not keen on the charge that it should have detected some of the programme in some of its twice-yearly inspection visits. It argues that its remit was simply to inspect the two reactors, one laboratory and one storage facility at Tuwaitha. It also pleads a lack of money. Its budget of $\$ 60$ million and 200 inspectors covers 1,000 reactors worldwide, and "Iraq's two small reactors were not its biggest priority".

Bronwen Maddox

\title{
Faculty pay up down under
}

\section{Sydney}

AUSTRALIAN universities should have a better chance of recruiting and retaining faculty, especially from overseas, now that their employees have won a major pay raise and are due a second, smaller increase over the next two years.

After years of decline of academic salaries in relation to other occupations in Australia, the central wage-fixing body, the Industrial Relations Tribunal, recently increased the pay scales for university staff by 12 to 16 per cent. And Australian academic unions are about to apply for further pay increases of up to 7 per cent. Under the rules for the latest round in Australia's centralized pay bargaining process, the Federated Australian University Staff Association and the Union of Australian College of Academics can expect increases of at least 2.5 per cent.

With the changes announced so far, a full professor's salary will increase by 12 per cent in stages to reach $\mathbf{A} \$ 76,000$ (about US\$60,000) by July 1992. Increases for junior staff are better, with junior lecturer salary levels increasing by 10 to 20 per cent to between $A \$ 40,000$ and $A \$ 47,500$. Associate professors will earn from $\mathrm{A} \$ 59,000$ to $\mathrm{A} \$ 65,000$. PLANETARY SCIENCE

\section{Deep freeze for Galileo}

\section{Washington}

THIS week, scientists at the National Aeronautics and Space Administration's (NASA) Jet Propulsion Laboratory will find out whether they have managed to free the Galileo Jupiter probe's main antenna, which has remained obstinately half unfurled ever since NASA first tried to open it in April. In the latest attempt to solve the problem last week, the craft was rotated, shading the antenna from the Sun for 50 hours to cool parts of the structure by as much as $100^{\circ} \mathrm{C}$.

Fully unfurled, Galileo's main antenna looks like an inverted umbrella. But several of the carbon fibre ribs that support the structure have jammed, leaving it lopsided and functionally useless. This is a serious problem: if the antenna cannot be opened before Galileo's Jupiter rendezvous in 1995, most of the data from its 11 on-board instruments will never be relayed back to Earth.

NASA officials believe that cooling the antenna can solve the problem. The offending items are thought to be small metal alloy pins that keep the carbon fibre ribs correctly aligned, and project scientists hope that the differing thermal expansion of the two materials can be exploited to free the antenna. Last week's 50-hour
The unions say these increases are justified not only because of the relative decline in academic salaries but also because of major changes in both the university system and methods of allocating research funds.

The system changes include wholesale amalgamation of smaller college campuses, upgrading of several institutes to university status, a drive to get universities to earn more money from other sources and a major increase in the number of students in the system. While the last trend has resulted in overcrowding on campus and protests over campus conditions, one major surprise of the drive to attract students was a 13 per cent increase in university science enrolments. The increase occurred after several years of decline.

Another change, begun in 1988 , has been to reduce the grants given to universities and redirect that money to the Australian Research Council for allocation in the form of grants to projects. This more centralized method of allocating research funds has emphazised larger projects and put more strain on junior staff, says Simon Marginson, research officer of the university staff association.

Mark Lawson

freeze is the second attempt to release the antenna by cooling - a similar manoeuvre last month, which lasted 32 hours, failed to do the job. Heating the antenna in the full glare of the Sun, which was tried in May, also proved unsuccessful. Programme manager Donald Ketterer, from NASA's headquarters in Washington, says that alternate cooling and heating manoeuvres will continue until the antenna opens.

The main antenna can relay 130,000 bits of information per second back to Earth, and with a back-up low-gain antenna capable of transmitting only 10 bits of information a second, a functioning main antenna is vital for the success of the $\$ 1,600$ million mission. Ketterer says that, without the main antenna, a single image from the craft's solid state imaging device would take several days, rather than a few seconds to transmit.

Jet Propulsion Laboratory scientists should know if the cooling manoeuvre has worked on Tuesday this week (20 August), shortly after Nature goes to press. If the jammed ribs have sprung free, telemetry signals from Galileo will reveal that a small wobble in the craft's flight, caused by the lopsided antenna, has stopped.

Peter Aldhous 